\title{
NON-DARCY FLOW EVALUATION OF UNCONSOLIDATED POROUS MEDIA IN A CLOSED LOOP PERMEAMETER
}

\author{
H. E. Maciel, IBSTRACT \\ and L.D.T. Câmara \\ A new closed loop permeameter was implemented in this work to study the \\ fluid flow through two different unconsolidated porous media. An apparent \\ permeability, similar to that proposed by Barree and Conway, was described \\ Instituto Politécnico da UERJ \\ Dep. Engenharia Mecânica e Energia \\ in this work in terms of the absolute permeability combined with a new \\ fluid property description, the inertial contribution factor that accounts for \\ the domain of viscous and inertial forces. Such approach discriminate those \\ properties of the rock as intrinsic permeability from those related to the \\ fluid as the inertial contribution factor. The apparent permeability equation \\ of Barree and Conway was applied to different intervals of the experimental \\ data in which it was possible to obtain the Forchheimer coefficients as well \\ as the inertial contribution factors according to each interval. Two different \\ types of unconsolidated porous media materials were utilized in the new \\ Closed Loop Permeameter, sand (1-2 mm) and glass spheres $(3.96 \mathrm{~mm})$. \\ The equation of Barree and Conway provided a great agreement fitting the \\ experimental data in a wide non-Darcy Reynolds number range. It was \\ observed an increase in the Forchheimer coefficient and decrease in the \\ apparent permeability with the flow rate increase. The results indicate a \\ correlation between the permeability and the inertial effects in the non- \\ Darcy turbulent regions in which the porous media materials with low \\ permeability values are probably more subjected to flow losses due to the \\ Received: November 10, 2018 \\ inertial effects. \\ Revised: January 30, 2019 \\ Accepted: February 28, 2019 \\ Keywords: closed loop permeameter; non-Darcy; Forchheimer
}

\section{NOMENCLATURE}

$\mathrm{p}$ pressure, $\mathrm{Pa}$

$\mathrm{L}$ length, $\mathrm{m}$

Q volumetric flow, $\mathrm{m}^{3} / \mathrm{s}$

$\mathrm{Re}_{\mathrm{m}} \quad$ Reynolds number, -

$\mathrm{k}_{\mathrm{app}} \quad$ apparent permeability, $\mathrm{m}^{2}$

$\mathrm{k}$ permeability, $\mathrm{m}^{2}$

$\mathrm{L}^{*} \quad$ characteristic length, $\mathrm{m}$

$\mathrm{S}_{\mathrm{y}} \quad$ specific interfacial area, $\mathrm{m}^{-1}$

\section{Greek symbols}

$v \quad$ velocity, $\mathrm{m} / \mathrm{s}$

$\rho \quad$ density, $\mathrm{kg} / \mathrm{m}^{3}$

$\mu \quad$ dynamic viscosity, Pa.s

$\delta \quad$ inertial contribution factor, $\mathrm{m}^{2}$

$\beta \quad$ Forchheimer coefficient, $\mathrm{m}^{2}$

\section{INTRODUCTION}

The Forchheimer equation is widely utilized to study fluid flow phenomena in porous media under flow regime where Darcy's model fail to represent adequately. Increasing the interstitial fluid velocity leads to flow regimes in which the inertial phenomena is significant and must be considered. Forchheimer (1901) included into Darcy's model a second order in terms of velocity $(v)$ to account for the microscopic inertial effect (Zeng and Grigg, 2006)

$$
-\frac{d p}{d L}=\frac{\mu v}{k}+\beta \rho v^{2}
$$

where $\beta$ is the Forchheimer coefficient.

The great application of non-Darcy flow models is in the reservoirs fluid flow study due to the great economic importance of hydrocarbon production in such porous media reserves (Geertsma, 1974; Holditch and Morse, 1976; Wu et al., 2011; Lai et al., 2012; Zeng and Grigg, 2006; Firoozabadi and Katz, 1979; Amao, 2007). It can be observed research groups more interested in the study of the theoretical aspects of non-Darcy models as in the works of Andrade et al., 1999; Soulaine and Quintard, 2014; Wu et al., 2011; Moutsopoulos and Tsihrintzis, 2005; Zeng and Grigg, 2006; Wang et al., 2014; Amao, 2007. Also there are relevant experimental studies being carried out to support the development of such models (Lai et al., 2012; Dukhana et al. 2014; Beavers et al. 1973; Firoozabadi and Katz, 1979; Sobieski and Trykozko, 2014; Geertsma, J., 1974; Jambhekar, 2011; Sobieski and Trykozko, 2014; Beavers, 1973).

Barree and Conway (2004) proposed a new formulation which describes the Forchheimer equation in a form similar to the Darcy equation with an apparent permeability. They carried out an 
experimental analysis and observed that to well represent the non-Darcy flow in porous media the Forchheimer coefficient as well as the apparent permeability must vary with the flow rate. The new formulation of Barree and Conway (2004) has been successfully utilized by some authors as $\mathrm{Wu}$ et al., 2011, Lai et al. 2012 and Jambhekar 2011 in the modeling of non-Darcy fluid flow in porous media. Wu et al., 2011, applied the Barree and Conway model into a reservoir numerical simulator to study non-Darcy flow in porous media. Lai et al., 2012, observed that the Barree and Conway approach can represent successfully the non-Darcy flow of nitrogen gas through proppant packs in all the domain studied from low to high-flow rates. The usual application of Forchheimer equation did not correlate the experimental data at high flow rates as the quadratic and cubic models, respectively, overestimates and underestimates the pressure drop at high gas flow rates. Lai and coauthors concluded that the Barree and Conway (2004) model can represent successfully all the non-Darcy flow domain without the Forchheimer model limitations at high flow rates. Jambhekar, 2011, applied the Forchheimer model in the analysis of experimental data of non-Darcy air flow into a well-structured $\mathrm{Ni}$-alloyed steel porous media. He was interested in the heat transfer improvement of the metallic porous media for cooling applications. Jambhekar obtained the intrinsic permeability, apparent permeability and the Forchheimer coefficient from the experimental data correlation with the Barree and Conway (2004) model approach. The author observed that the best model representation was obtained assuming a Forchheimer coefficient varying with the Reynolds number.

The previous success of Barree and Conway (2004) formulation to represent non-Darcy flow in porous media (Wu et al., 2011, Lai et al. 2012 and Jambhekar 2011) shows the model approach potential which can be explored in more detail. The model approach was evaluated and studied in which the same apparent permeability was described in this work in terms of the absolute permeability combined with a new fluid description, the inertial contribution factor that accounts for the domain of viscous and inertial forces. Such approach discriminates those properties of the rock as intrinsic permeability from those related to the fluid as the inertial contribution factor. The new approach, following the Barree and Conway (2004) formulation, was evaluated through the new experimental unit, the Closed Loop Permeameter, which was implemented to study two types of unconsolidated porous media materials, sand and glass spheres. The apparent permeability equation of Barree and Conway was applied to different intervals of the experimental data in which was possible to obtain the Forchheimer coefficient as well as the inertial contribution factor according to each interval.

\section{MATHEMATICAL MODEL}

The Forchheimer equation can be written in a finite form that corresponds to

$$
\frac{\Delta p}{\Delta L}=\frac{\mu v}{k}+\beta \rho v^{2}
$$

in which each term can be multiplied by the area A leading to following equation in terms of the volumetric flow rate, $\mathrm{q}$

$$
\frac{\Delta p}{\Delta L}=\frac{\mu q}{k A}+\frac{\beta \rho v}{A}
$$

The Eq. (2) can be rewritten and inverted leading to

$$
\begin{gathered}
\frac{q}{\Delta p}=\frac{A}{\mu L}\left(\frac{k\left(\frac{\mu}{\beta \rho v}\right)}{\left(\frac{\mu}{\beta \rho v}\right)+k}\right) \cdots \frac{q}{\Delta p}=\frac{A}{\mu L}\left(\frac{k \delta}{k+\delta}\right) \\
\frac{q}{\Delta p}=\frac{A}{\mu L} k_{a p p}
\end{gathered}
$$

The Eq. 3 is similar to Barree and Conway (2004) model despite the way the apparent permeability, $k_{a p p}$, is obtained as the combination between the absolute permeability, $k$, and the new property description, the inertial coefficient factor, $\delta=\mu /(\beta \rho v)$. The apparent permeability, $k_{a p p}$, is described below in terms of the permeability, $k$, and the inertial coefficient factor, $\delta$.

$$
\begin{aligned}
& k_{\text {app }}=\frac{k \delta}{k+\delta} \\
& \frac{1}{k_{\text {app }}}=\frac{1}{k}+\frac{1}{\delta}
\end{aligned}
$$

From Eq. 5 it can be observed that the properties $\mathrm{k}$ and $\delta$ has a peculiar relationship which can be represented as a system of resistances in series like $\mathrm{R}_{\text {kapp }}=\mathrm{R}_{\mathrm{k}}+\mathrm{R}_{\delta}$ in which $\mathrm{R}_{\mathrm{k}}$ and $\mathrm{R}_{\delta}$ are, respectively, the resistance due to the porous media and the resistance due to the inertial effect. Analyzing the term $1 / \delta=(\beta \rho v) / \mu$ in Eq. 5 it can be observed that it is proportional to the term $\beta$ which is called by some authors as coefficient of inertial resistance (Geertsma, J., 1974; Carnogurska et al. 2012) due to the inertial losses related to the acceleration and deceleration effects of the fluid as it goes through the porous media.

The introduction of the inertial contribution factor, $\delta=\mu /(\beta \rho v)$, in the study of non-Darcy flow is 
interesting as such approach leads to a modeling (Eq. 3) that discriminates the rock properties as intrinsic permeability $(k)$ to those related to the fluid as the inertial contribution factor $(\delta)$.

\section{EXPERIMENTAL SECTION}

Fig. 1 shows the new implemented Closed Loop Permeameter, utilized to obtain the experimental data of permeability. The pump was utilized to flow water from a tank to the top of the porous media bed. The water column above the bed can be adjusted controlling the two valves so it is converted into pressure drop along the porous media bed which is combined with the fluid flow rate measured in the rotameter. The data of pressure drop and fluid flow is utilized in the models for the calculation of the properties. As a closed loop system, the water collected in the tank returns to the pump and again it is pumped to the top of the porous media.

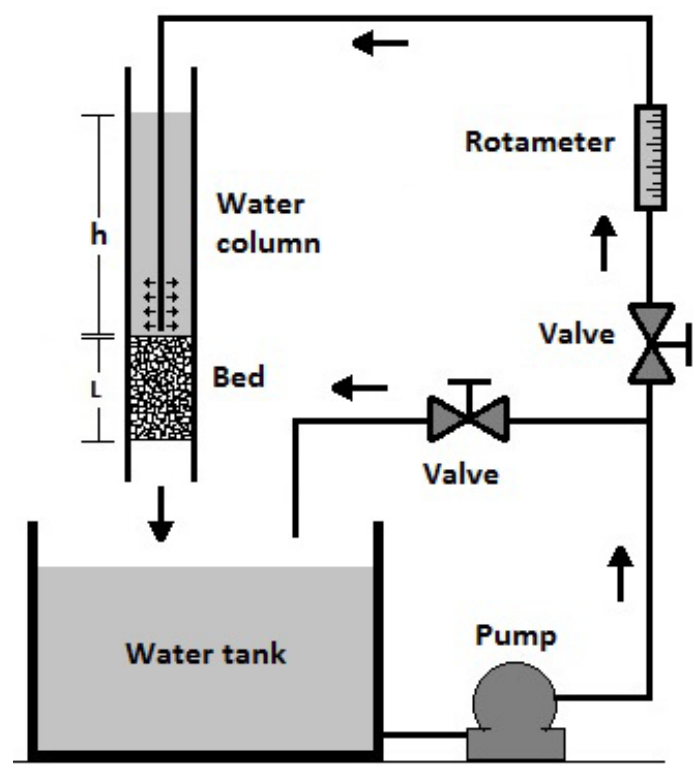

Figure 1. The new Closed Loop Permeameter for permeability measurement.

The following Fig. 2 shows the two types of porous media that were utilized in the Closed Loop Permeameter of Fig.1., in which on the left, Fig. 2A, there is the glass spheres (average size of $3.96 \mathrm{~mm}$ ) and on the right, Fig. 2B, there is the sieved sand (average size in the range of $1-2 \mathrm{~mm}$ ).
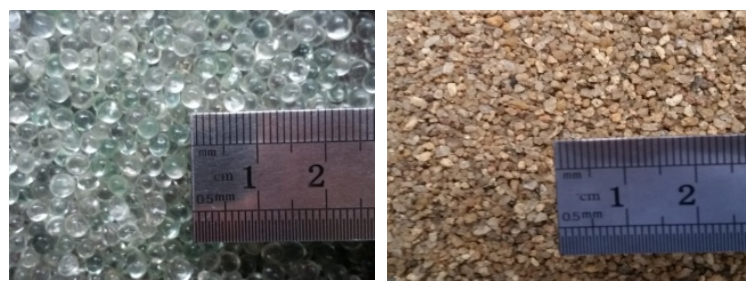

Figure 2. Two types of porous media utilized in the experiments.
The Reynolds number $\left(\operatorname{Re}_{\mathrm{m}}\right)$ utilized in this work is similar to that utilized by Jambhekar, (2011),

$$
\operatorname{Re}_{m}=\frac{\rho v L *}{\mu}
$$

where $\rho, v, L^{*}$ and $\mu$ represents, respectively, the density, velocity, characteristic length and dynamic viscosity of the fluid. The characteristic length is obtained from the specific interfacial area which is defined as the contact area between the solid and fluid phase per unit of volume. The following Table 1 presents the characteristic length and the specific interfacial area for the two porous media utilized in this work, the glass spheres and the sand, and by Jambhekar, 2011, a well-structured Ni-alloyed steel porous media.

Table 1. Porous media properties.

\begin{tabular}{|l|c|c|}
\hline & $\begin{array}{l}\text { Characteristic } \\
\text { length, } \mathrm{L}[\mathrm{m}]\end{array}$ & $\begin{array}{l}\text { Specific } \\
\text { interfacial area, } \\
\mathrm{s}_{\mathrm{V}}\left[\mathrm{m}^{-1}\right]\end{array}$ \\
\hline Glass spheres & 0.000966 & 1034.5 \\
\hline Sand & 0.000175 & 5688.4 \\
\hline Ni-alloyed steel & 0.001110 & 901.0 \\
\hline
\end{tabular}

The bed porosity of the two porous media studied in this work is obtained by the water volume necessary to fill the total pores space of a certain volume of the porous media.

\section{RESULTS AND DISCUSSION}

The Figs. 3 and 4 presents the experimental data of pressure drop along length $(\Delta \mathrm{p} / \mathrm{L})$ according to the modified Reynolds number $\left(\mathrm{Re}_{\mathrm{m}}\right)$ described in Eq. 6 . In Fig. 3 the experimental data of Jambhekar (2011) was compared to the experiments obtained in this work for glass spheres.

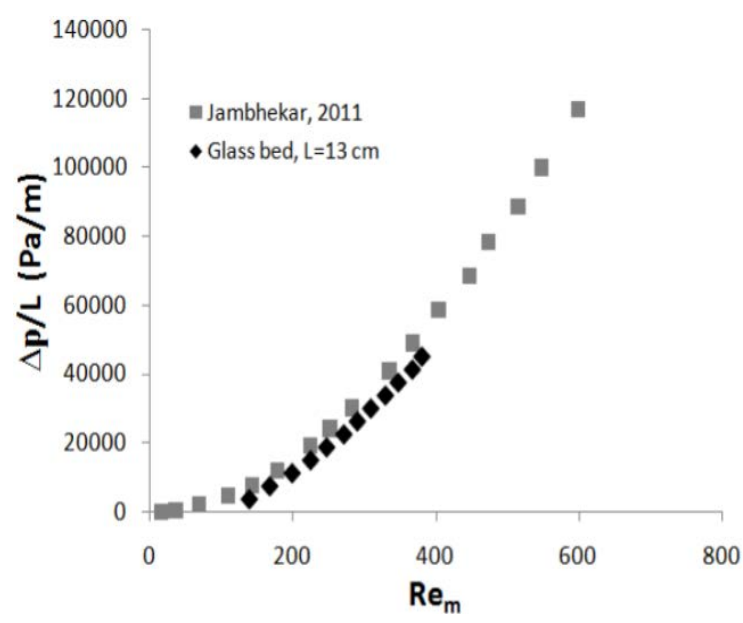

Figure 3. Experimental data of $\Delta \mathrm{p} / \mathrm{L}$ vs $\mathrm{Re}_{\mathrm{m}}$; Glass bed.

As can be seen in Fig. 3 the experimental data 
of pressure drop along length $(\Delta \mathrm{p} / \mathrm{L})$ are very close despite the type of porous media as well as the fluid utilized. Jambhekar (2011) utilized compressed air flow through a well-structured $\mathrm{Ni}$-alloyed steel porous media while in this work it was utilized water flow through an unconsolidated glass porous media. The great similarity is observed in the porous media property as it can be seen in Table 1 for the characteristic length as well as the specific interfacial area which are very close for both porous media. The characteristic length of Jambhekar's (2011) porous media is only $14.9 \%$ greater than that for glass porous media of this work which can be the reason for such close experimental results, observed in Fig. 3, in terms of pressure drop along the length $(\Delta \mathrm{p} / \mathrm{L})$. Also the Reynolds number limit obtained by Jambhekar, which indicates the Darcy and non-Darcy transition domain, is very close to the value acquired in this work. Jambhekar obtained a Reynolds number limit of 180 and in this work the value is around 200, as can be seen in Fig. 4.

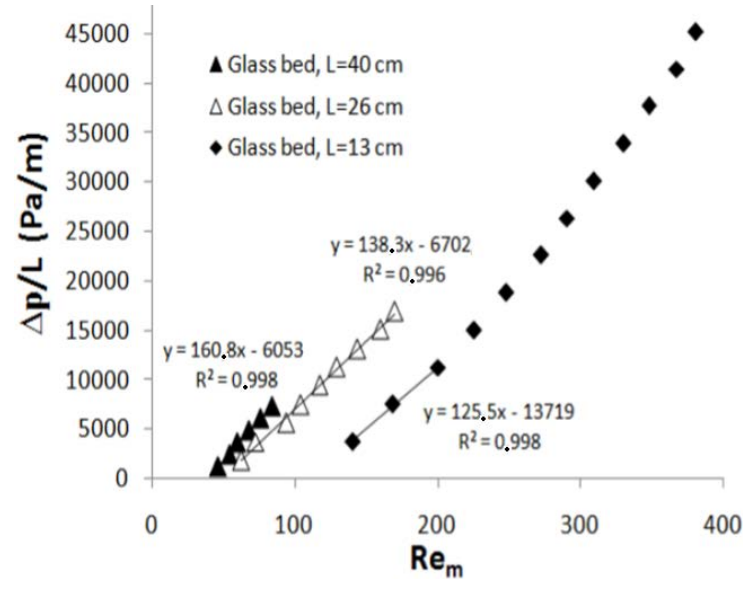

Figure 4. Experimental data of $\Delta \mathrm{p} / \mathrm{L}$ vs $\operatorname{Re}_{\mathrm{m}}$; Glass bed.

From Fig. 4 it can be seen the experimental linear behavior for $\mathrm{Re}_{\mathrm{m}}$ lower than 200, showing for all the glass bed sizes of each experiment almost the same angular coefficient. The linear behavior indicates Darcy domain with the same permeability as the slopes of the straight lines are almost the same. There is a little variation in the slopes $\left(\operatorname{Re}_{\mathrm{m}}\right.$ lower than 200) as a consequence of variation in the porous media structure and arrangement due to the spheres bed preparation in each experiment. The non-Darcy behavior can be observed for $\mathrm{Re}_{\mathrm{m}}$ higher than 200 as the pressure drop increases along the flow rate increase.

The experimental results of Fig. 4 for the glass bed size of $13 \mathrm{~cm}$ were plotted in Fig. 5 in terms of flow rate versus pressure. In Fig. 5 the first region corresponds to the linear behavior of Darcy flow $\left(\operatorname{Re}_{\mathrm{m}}\right.$ lower than 200) followed by the non-Darcy region which was discretized allowing the best linear behavior application of Eq. 3 that results in the apparent permeability, $k_{\text {app }}$. From Fig. 5 it can be observed that the linear behavior consideration in non-Darcy region is plausible as the linear equations do not deviate outside the flow rate bar error. All linear regressions of each segment considered show a great correlation between the linear model and the experiments as the correlation coefficient is higher than 0.998. The flow rate error included in Fig. 5 was acquired from the rotameter measurements.

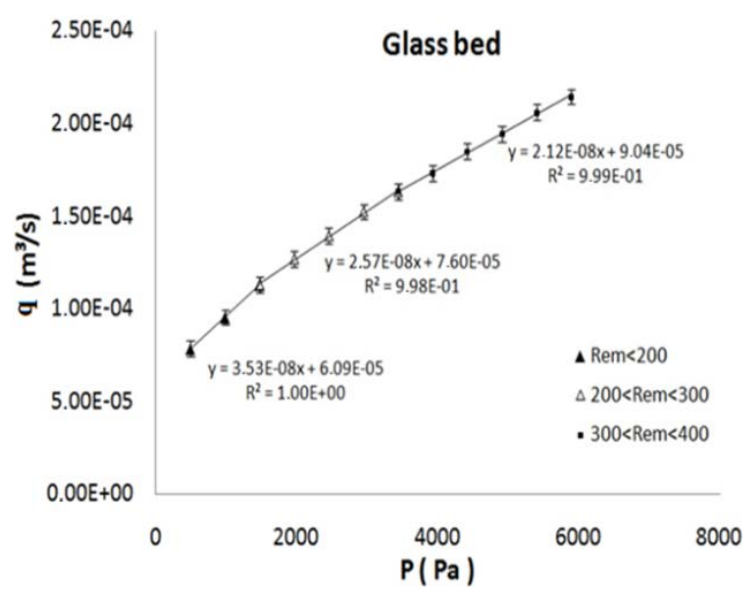

Figure 5. Experimental data of flow rate $\left(\mathrm{m}^{3} / \mathrm{s}\right)$ vs pressure $(\mathrm{Pa})$; glass bed size of $13 \mathrm{~cm}$.

The results of absolute permeability $(k)$, apparent permeability $\left(k_{a p p}\right)$, inertial contribution factor $(\delta)$ and the Forchheimer parameter $(\beta)$ are shown in Table 2 and 3 , according to modified Reynolds number regions. The Reynolds number range for regions 1,2 and 3 are the following, respectively, $\operatorname{Re}<200,200 \leq \operatorname{Re}<290$ and $\operatorname{Re} \geq 290$. As it can be seen the absolute permeability is the same as it is a rock property. The absolute permeability is obtained in the first interval which is the region of low Reynolds domain without the flow turbulence effects. This constant value of permeability is utilized in all the intervals allowing the determination of nonDarcy properties $\left(k_{a p p}, \delta\right.$ and $\left.\beta\right)$ through the application of Eqs. 3, 4 and 5. In the first interval the resistance to flow related to inertial effect $(1 / \delta)$ is so low (high value of inertial contribution factor, $\delta$ ) due to Darcy flow without the inertial effect. Therefore the inertial contribution factor, $\delta$, is higher than the absolute permeability $(\delta \gg k)$ and such inequality in Eq. 5 leads to $k_{a p p} \rightarrow k$ in which the Barree and Conway model of Eq. 3 becomes the classical Darcy model. The same understanding is obtained through the inertial contribution factor equation, $\delta=\mu /(\beta \rho v)$, as in the first Darcy region the Forchheimer parameter tends to zero, $\beta \rightarrow 0$, and $\delta \rightarrow \infty$ resulting in $k_{a p p} \rightarrow k$. From Tables 2 and 3 it can be seen that in the first Darcy region the absolute permeability is equal to the apparent permeability as the resistance to flow related to inertial effect is so low $(1 / \delta \rightarrow 0)$ so the inertial contribution factor is so high $(\delta \rightarrow \infty)$. Increasing the Reynolds number there is an increase in the 
resistance to flow $(1 / \delta)$ due to the increase of the inertial effect. Also the Forchheimer parameter increases following the decrease in the inertial contribution factor and apparent permeability.

Table 2. Properties of glass porous media.

\begin{tabular}{|c|c|c|c|}
\hline & $\begin{array}{c}k\left(\mathrm{~m}^{2}\right) \\
* 10^{-9}\end{array}$ & $\begin{array}{c}k_{a p p}\left(\mathrm{~m}^{2}\right) \\
* 10^{-9}\end{array}$ & $\begin{array}{c}\delta\left(\mathrm{m}^{2}\right) \\
* 10^{-9}\end{array}$ \\
\hline 1. Darcy & 2.49 & 2.49 & $\delta \rightarrow \infty$ \\
\hline 2. Non-Darcy & 2.49 & 2.13 & 14.90 \\
\hline 3. Non-Darcy & 2.49 & 1.76 & 6.00 \\
\hline
\end{tabular}

Table 3. Properties of glass porous media.

\begin{tabular}{|c|c|c|}
\hline & $\beta\left(\mathrm{m}^{-1}\right)$ & $1 / \delta\left(\mathrm{m}^{-2}\right) * 10^{9}$ \\
\hline 1. Darcy & $\beta \rightarrow 0$ & $1 / \delta \rightarrow 0$ \\
\hline 2. Non-Darcy & 262 & 0.067 \\
\hline 3. Non-Darcy & 477 & 0.167 \\
\hline
\end{tabular}

The next Fig. 6 shows the experimental results for sand bed utilized in the same experimental apparatus (Fig. 1). Also the results are plotted in terms of pressure drop along the length $(\Delta \mathrm{p} / \mathrm{L})$ according to modified Reynolds number $\left(\mathrm{Re}_{\mathrm{m}}\right)$. From Fig. 6 it can be observed the same experimental behavior as that shown in Fig. 4 in which there are two well defined regions for Darcy and non-Darcy flow domain. In this case of sand porous media the Reynolds number $\mathrm{Re}_{\mathrm{m}}$ limit for Darcy flow is around 12 which is lower than glass porous media $\left(\operatorname{Re}_{m}\right.$ of 200). Analyzing the porous media data presented in Table 1 it can be observed that the specific interfacial area of sand porous media is $452 \%$ higher than that for glass porous media. Therefore there is an inverse relation between the Reynolds number $\mathrm{Re}_{\mathrm{m}}$ and the specific interfacial area of the porous media utilized as the Reynolds number decreased with the increase in the specific interfacial area. In the Darcy region $\left(\operatorname{Re}_{\mathrm{m}}\right.$ lower than 12) also it can be observed straight lines with the same slope which leads to the same value of permeability. The non-Darcy behavior can be observed for $\mathrm{Re}_{\mathrm{m}}$ higher than 12 as the pressure drop increases along the flow rate increase.

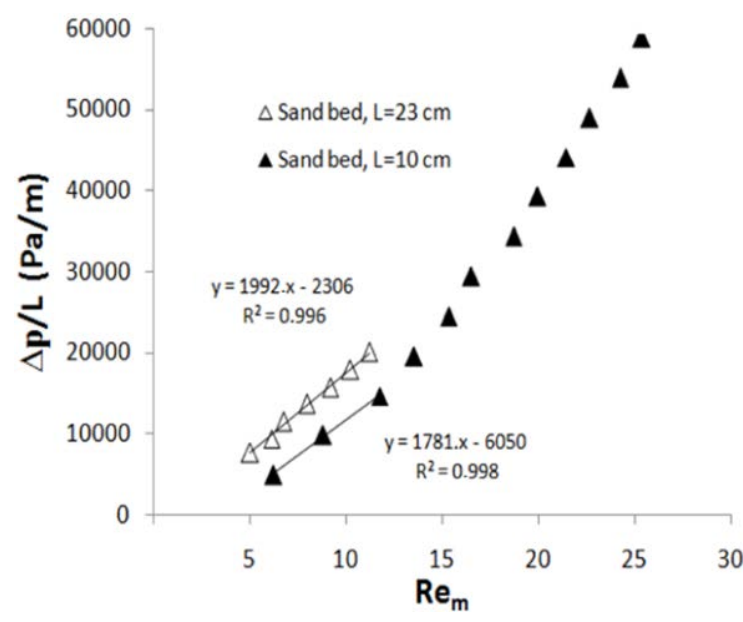

Figure 6. Experimental data of $\Delta \mathrm{p} / \mathrm{L}$ vs $\mathrm{Re}_{\mathrm{m}}$; Sand bed.
The experimental results of Fig. 6 for the glass bed size of $10 \mathrm{~cm}$ were plotted in Fig. 7 in terms of flow rate versus pressure. In Fig. 7 the first region corresponds to the linear behavior of Darcy flow $\left(\mathrm{Re}_{\mathrm{m}}\right.$ lower than 12) followed by the non-Darcy region which was discretized allowing the best linear application of Eq. 3 that results in the apparent permeability, $\mathrm{k}_{\mathrm{app}}$. Similar to the glass porous media results of Fig. 5, in the sand experimental results of Fig. 7 the linear behavior consideration in non-Darcy region is plausible as the linear equations do not deviate outside the flow rate bar error. As in the glass results (Fig. 5), all linear regressions of each segment show a great correlation between the linear model and the experiments as the correlation coefficient is higher than 0.994 .

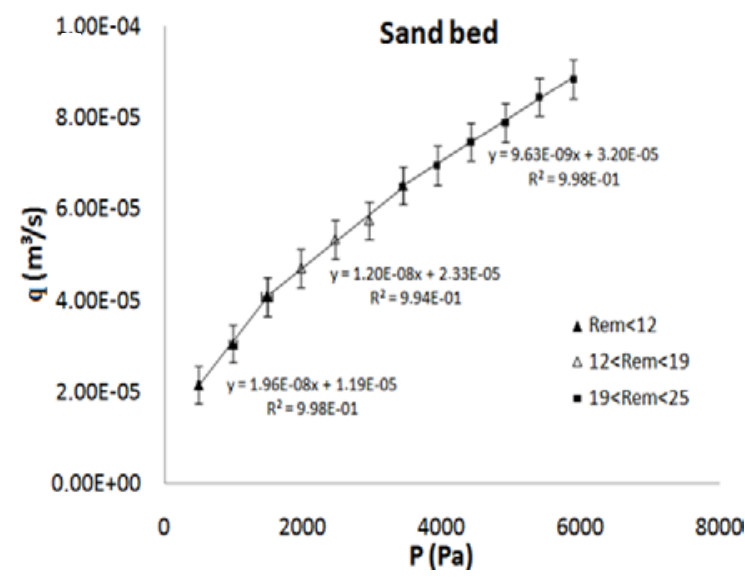

Figure 7. Experimental data of flow rate $\left(\mathrm{m}^{3} / \mathrm{s}\right)$ vs pressure $(\mathrm{Pa})$; sand bed size of $10 \mathrm{~cm}$.

The Tables 4 and 5 presents the results from Fig. 7 in terms of absolute permeability (k), apparent permeability $\left(\mathrm{k}_{\mathrm{app}}\right)$, inertial contribution factor $(\delta)$ and the Forchheimer parameter $(\beta)$, according to modified Reynolds number regions. The Reynolds number range for regions 1,2 and 3 are the following, respectively, $\operatorname{Re}<12, \quad 12 \leq \operatorname{Re}<19$ and $\operatorname{Re} \geq 19$. Also the absolute permeability is obtained in the first interval which is the region of low Reynolds domain without the flow turbulence effects. This constant value of permeability is utilized in all the intervals allowing the determination of non-Darcy properties $\left(\mathrm{k}_{\mathrm{app}}, \delta\right.$ and $\beta$ ). Also the Forchheimer parameter increases following the decrease in the inertial contribution factor and apparent permeability. As expected the absolute permeability of sand porous media is lower than that for glass porous media due to lower grain size of the sand utilized $(1-2 \mathrm{~mm})$ if compared to glass grain size $(3.96 \mathrm{~mm})$. Also, comparing the results for glass porous media (Tables 2 and 3) and sand porous media (Tables 4 and 5), it can be seen that the Forchheimer parameter is very higher for sand bed which indicates a higher inertial effect for this lower permeability porous material. It is also observed a higher inertial effect for sand 
porous media in the resistance to flow term $(1 / \delta)$ which is $652 \%$ and $396 \%$ higher for non-Darcy 2 and 3 regions, respectively.

Table 4. Properties of sand porous media.

\begin{tabular}{|c|c|c|c|}
\hline & $\begin{array}{r}k\left(\mathrm{~m}^{2}\right) \\
* 10^{-9}\end{array}$ & $\begin{array}{c}k_{a p p}\left(\mathrm{~m}^{2}\right) \\
* 10^{-9}\end{array}$ & $\begin{array}{c}\delta\left(\mathrm{m}^{2}\right) \\
* 10^{-9}\end{array}$ \\
\hline 1. Darcy & 1.25 & 1.25 & $\delta \rightarrow \infty$ \\
\hline 2. Non-Darcy & 1.25 & 0.767 & 1.98 \\
\hline 3. Non-Darcy & 1.25 & 0.615 & 1.21 \\
\hline
\end{tabular}

Table 5. Properties of sand porous media.

\begin{tabular}{|c|c|c|}
\hline & $\beta\left(\mathrm{m}^{-1}\right)$ & $1 / \delta\left(\mathrm{m}^{-2}\right) * 10^{9}$ \\
\hline 1. Darcy & $\beta \rightarrow 0$ & $1 / \delta \rightarrow 0$ \\
\hline 2. Non-Darcy & 5870 & 0.505 \\
\hline 3. Non-Darcy & 6590 & 0.826 \\
\hline
\end{tabular}

The higher Forchheimer parameters in this work for the lower permeability of sand porous media was also observed by Zeng and Grigg, 2006. The authors observed, as in next Table 6 for different porous medium, that the Forchheimer parameter increases as the porosity (por.\%) and the permeability decrease. These results indicate a correlation between the permeability and the inertial effects in the non-Darcy turbulent regions in which the porous media materials with low permeability values are probably more subjected to flow losses due to the inertial effects.

Table 6. Zeng and Grigg (2006) experimental data.

\begin{tabular}{|c|c|c|c|}
\hline & $\begin{array}{c}k\left(\mathrm{~m}^{2}\right) \\
* 10^{15}\end{array}$ & $\begin{array}{c}\beta\left(\mathrm{m}^{-1}\right) \\
* 10^{8}\end{array}$ & $\begin{array}{c}\text { Por. } \\
\%\end{array}$ \\
\hline Dakota sandstone & 3.48 & 157.88 & 14 \\
\hline Indiana Limestone & 21.6 & 36.00 & 15 \\
\hline Berea sandstone & 196 & 2.88 & 18 \\
\hline
\end{tabular}

\section{CONCLUSIONS}

The new implemented Closed Loop Permeameter-CLP was able to measure with accuracy the permeability of the two unconsolidated porous media materials studied which is in accordance to the values observed in the literature. The CLP was also able to measure the fluid flow in non-Darcy conditions providing the fluid flow pressure drop and flow rate data necessary to be utilized in the modified Forchheimer model. The CLP unit operation is simple and the fluid flow data can be easily obtained through the measurements of water column above the porous media and fluid flow rate for each condition.

The description of the new property, the inertial contribution factor, in the Barree and Conway nonDarcy model approach is interesting as it discriminates those properties of the rock as intrinsic permeability from those related to the fluid as the inertial contribution factor. In such approach the new inertial contribution factor can be considered as a parallel property with the permeability. The Barree and Conway model with an apparent permeability provided a great agreement fitting the experimental data in non-Darcy regions according to a modified Reynolds number which is obtained through the characteristic length of the porous media utilized. From the two types of porous media utilized, sand (1$2 \mathrm{~mm}$ ) and glass $(3.96 \mathrm{~mm})$, it can be observed that the specific interfacial area of sand porous media is $452 \%$ higher than that for glass porous media. There is an inverse relation between the modified Reynolds number $\left(\operatorname{Re}_{\mathrm{m}}\right)$ and the specific interfacial area of the porous media utilized as the Reynolds number decreased with the increase in the specific interfacial area. It was observed an increase in the Forchheimer coefficient and decrease in the apparent permeability with the flowrate increase. The results indicate a correlation between the permeability and the inertial effects in the non-Darcy turbulent regions in which the porous media materials with low permeability values are probably more subjected to flow losses due to the inertial effects. The higher Forchheimer parameters in this work for the lower permeability of sand porous media was also observed by Zeng and Grigg, 2006.

\section{ACKNOWLEDGEMENTS}

The authors acknowledge the financial support from Capes, Faperj and CNPq.

\section{REFERENCES}

Amao, A. M., 2007, Mathematical Model for Darcy Forchheimer Flow with Applications to Well Performance Analysis, Master Thesis, Texas Tech University-USA.

Andrade Jr., J. S., Costa, U. M. S., Almeida, M. P., Makse, H. A., and Stanley, H. E., 1999, Inertial Effects on Fluid Flow through Disordered Porous Media, Physical Review Letters, Vol. 82, pp.52495252.

Barree, R. D., and Conway, M. W., 2004, Beyond Beta Factors: a Complete Model for Darcy, Forchheimer, and Trans-Forchheimer Flow in Porous Media, in: SPE Annual Technical Conference and Exhibition, Houston, Texas, USA, pp. 26-29.

Beavers, G. S., Sparrow, E. M., and Rodenz, D. E., 1973, Influence of Bed Size on the Flow Characteristics and Porosity of Randomly Packed Beds of Spheres, Journal of Applied Mechanics, Vol. 40, No. 3, pp. 655-660.

Carnogurska, M., Prihoda, M., Brestovic, T., Molinek, J., and Pyszko, R., 2012, Determination of Permeability and Inertial Resistance Coefficient of Filter Inserts Used in the Cleaning of Natural Gas, Journal of Mechanical Science and Technology, Vol. 26, No. 1, pp. 103-111. 
Dukhana, N. Bağcıb, O., and Özdemirb, M., 2014, Experimental Flow in Various Porous Media and Reconciliation of Forchheimer and Ergun Relations, Experimental Thermal and Fluid Science, Vol. 57, pp. 425-433.

Firoozabadi, A., and Katz, D. L., 1979, An Analysis of High Velocity Gas Flow through Porous Media, Journal of Petroleum Technology, Vol. 31, No. 02, pp. 211-216.

Geertsma, J., 1974, Estimating the Coefficient of Inertial Resistance in Fluid Flow through Porous Media, Society of Petroleum Engineers Journal, Vol. 14, No. 5, pp. 445-450.

Holditch, S. A., and Morse, R. A., 1976, The Effects of non-Darcy Flow on the Behavior of Hydraulically Fractured Gas Wells, Journal of Petroleum Technology, Vol. 28, No. 10, pp. 1169-1179.

Jambhekar, V. A., 2011, Forchheimer PorousMedia Flow Models -Numerical Investigation and Comparison with Experimental Data, Master Thesis, Stuttgart University, Germany.

Lai, B., Wu, Y. -S., and Miskimins, J. L., 2012, non-Darcy Porous-Media Flow According to the Barree and Conway Model: Laboratory and Numerical-Modeling Studies, in: SPE Rocky Mountain Petroleum Technology Conference, Vol. 17, No. 1, pp. 70-79.

Moutsopoulos, K. N., and Tsihrintzis, V. A., 2005, Approximate Analytical Solutions of the Forchheimer Equation, Journal of Hydrology, Vol. 309, No. 1-3, pp. 93-103.

Sobieski, W., and Trykozko, A., 2014, Darcy's and Forchheimer's Laws in Practice. Part 1. The Experiment, Technical Sciences, Vol. 17, No. 4, pp. 321-335

Soulaine, C., and Quintard, M., 2014, On the Use of a Darcy-Forchheimer Like Model for a Macro-Scale Description of Turbulence in Porous Media and its Application to Structured Packings, International Journal of Heat and Mass Transfer, Vol. 74, pp. 88-100.

Wang, Q., Zhan, H., and Tang, Z., 2014, Forchheimer Flow to a Well-Considering TimeDependent Critical Radius, Hydrology and Earth System Sciences, Vol. 18, No. 6, pp. 2437-2448.

Wu, Y.-S., Lai, B., and Miskimins, J. L., 2011, Simulation of non-Darcy Porous Media Flow According to the Barree and Conway Model, The Journal of Computational Multiphase Flows, Vol. 3, No. 2, pp. 107-122.

Zeng, Z., and Grigg, R., 2006, A Criterion for non-Darcy Flow in Porous Media, Transport in Porous Media, Vol. 63, No. 1, pp. 57-69. 